\title{
Nitric oxide switches on glycolysis through the AMP protein kinase and 6-phosphofructo-2-kinase pathway
}

\author{
Angeles Almeida ${ }^{1}$, Salvador Moncada ${ }^{2,4}$ and Juan P. Bolaños ${ }^{3}$
}

\begin{abstract}
After inhibition of cytochrome c oxidase by nitric oxide ${ }^{1-3}$, astrocytes maintain energy production by upregulating glycolysis ${ }^{4,5}$ - a response which does not seem to be available to neurons. Here, we show that in astrocytes, after inhibition of respiration by nitric oxide, there is a rapid, cyclic GMP-independent increase in the activity of 6phosphofructo-1-kinase (PFK1), a master regulator of glycolysis ${ }^{6}$, and an increase in the concentration of its most powerful positive allosteric activator ${ }^{7}$, fructose-2,6bisphosphate $\left(F 2,6 \mathrm{P}_{2}\right)$. In neurons, nitric oxide failed to alter $\mathrm{F} 2,6 \mathrm{P}_{2}$ concentration or PFK1 activity. This failure could be accounted for by the much lower amount of 6phosphofructo-2-kinase (PFK2, the enzyme responsible for $\mathrm{F}_{2,6 \mathrm{P}_{2}}$ biosynthesis ${ }^{8}$ ) in neurons. Indeed, full activation of neuronal PFK1 was achieved by adding cytosol from nitric oxide-treated astrocytes. Furthermore, using the small interfering RNA (siRNA) strategy ${ }^{9}$, we demonstrated that the rapid activation of glycolysis by nitric oxide is dependent on phosphorylation of the energy charge-sensitive AMP-

activated protein kinase, resulting in activation of PFK2 and protection of cells from apoptosis. Thus the virtual absence of PFK2 in neurons may explain their extreme sensitivity to energy depletion and degeneration ${ }^{4,5,10}$.
\end{abstract}

Recently, we observed that inhibition of respiration by nitric oxide results in differing responses in astrocytes and neurons ${ }^{5}$. This consists of a rapid up-regulation of glycolysis in astrocytes, which does not occur in neurons. We suggested that this difference may underlie the different susceptibility of the two types of cells to injurious stimuli, and have now investigated the mechanisms involved in the activation of the glycolytic pathway by nitric oxide in these cells.

Initially, we investigated whether endogenously-generated nitric oxide could affect glycolysis in the way that we previously observed using exogenous nitric oxide. The glycolytic response was activated both in astrocytes transfected with inducible nitric oxide synthase (iNOS) and in lipopolysaccharide-interferon- $\gamma$ (LPS-IFN- $\gamma$ )- treated astrocytes from neuronal NOS knockout $\left(n \mathrm{NOS}^{-/-}\right)$mice (Fig. 1a). In contrast, no glycolytic activation was observed in either LPS-IFN- $\gamma$-treated astrocytes from $i \mathrm{NOS}^{-/-}$mice (Fig. 1a) or in neurons after activation of nNOS with glutamate (Fig. 1b). When both cell types were exposed to an equal amount of nitric oxide $(1.4 \mu \mathrm{M}$ nitric oxide, released from $0.5 \mathrm{mM}$ DETA-NO, the lowest concentration that maximally inhibits respiration in each cell type $\mathrm{e}^{5}$ glycolysis was upregulated in astrocytes but not in neurons (Fig. 1c). Thus the two cell types respond to endogenous nitric oxide in the same way as they do to exogenous nitric oxide. For this reason we used exogenously applied nitric oxide to investigate the steps involved in the activation of the glycolytic pathway by nitric oxide.

Treatment with $1.4 \mu \mathrm{M}$ nitric oxide resulted in a time-dependent decrease in fructose-6-phosphate (F6P) and increase in fructose1,6-biphosphate $\left(\mathrm{F} 1,6 \mathrm{P}_{2}\right)$ concentrations (the substrate and product of PFK1, respectively) in astrocytes, but not in neurons (Fig. 1d). The specific PFK1 activity was found to be approximately fourfold higher in astrocytes (Fig. 1e). Furthermore, using specific polyclonal antibodies raised against PFK1 isoforms, muscle (M), liver (L) and brain (C), we showed that, although the constitutive protein expression of PFK1.M and PFK1.L was similar in both cell types, the expression of PFK1.C was approximately fourfold greater in astrocytes than in neurons (Fig. 1e). This suggests that this latter isoform has a function in the different responses of the two cell types to nitric oxide.

The time course that we observed for PFK1 activation is too short to involve changes in protein expression. Furthermore, allosteric regulation of PFK1.C by ATP and AMP has been demonstrated in other cells ${ }^{11}$. Because of this, we decided to investigate the allosteric-dependent changes in PFK1 function by measuring the relative PFK1 activity $\left(v / V_{\max }\right)^{12}$ in astrocytes and neurons in the presence of supernatant freshly obtained from untreated or nitric oxide-treated cells. Our results demonstrated that supernatant from untreated astrocytes, but not neurons, contained metabolite(s) that stimulated relative PFK1 activity in both astro-

${ }^{1}$ Unidad de Investigación, Hospital Universitario de Salamanca, 37007 Salamanca, Spain. ${ }^{2}$ The Wolfson Institute for Biomedical Research, University College London, Gower Street, London WC1E 6BT, UK. ${ }^{3}$ Departamento de Bioquímica y Biología Molecular, Universidad de Salamanca, Edificio Departamental, 37007 Salamanca, Spain. ${ }^{4}$ Correspondence should be addressed to S.M. (s.moncada@ucl.ac.uk) 


\section{LETTERS}
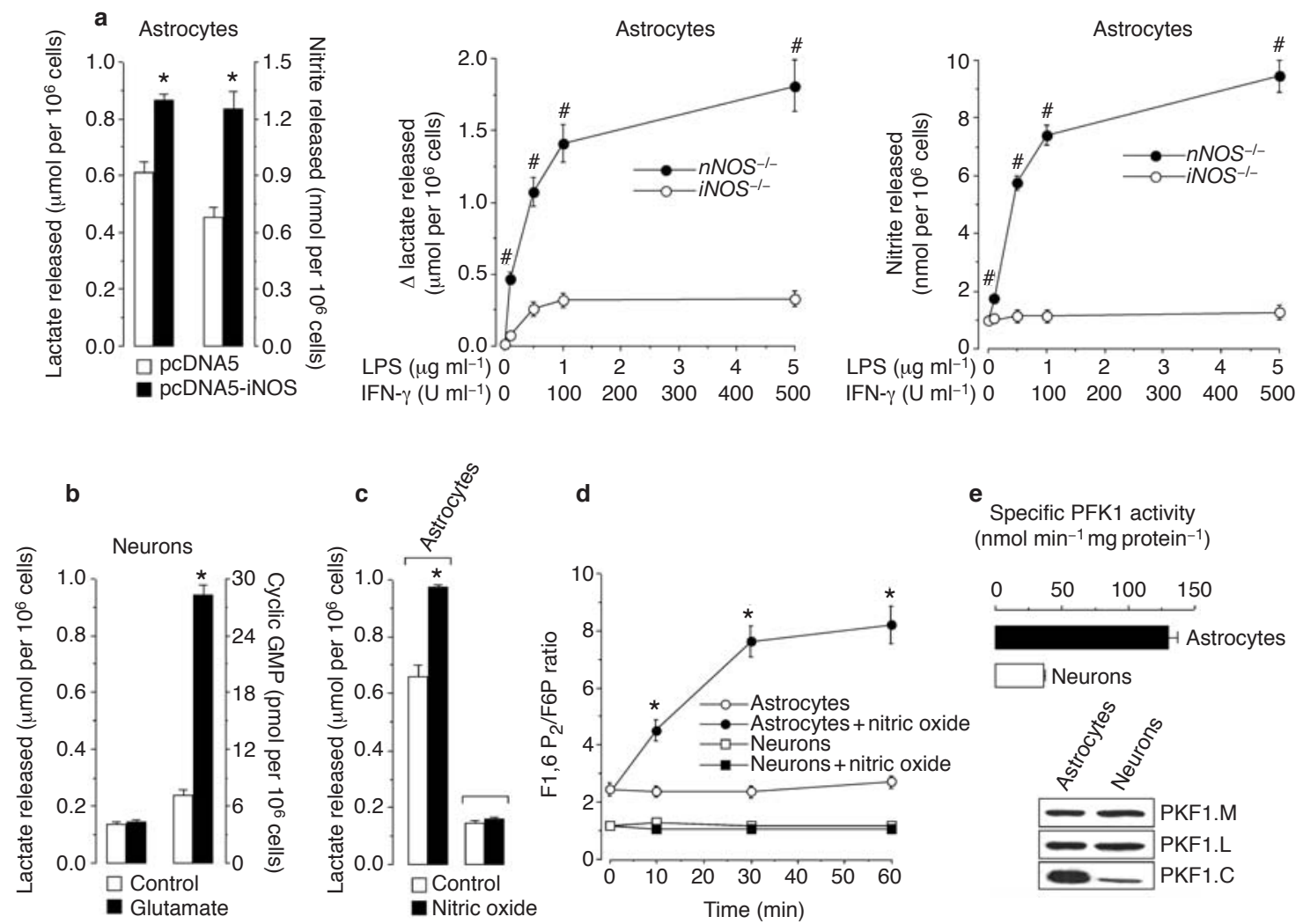

Figure 1 Nitric oxide activates glycolysis through PFK1. (a) Nitric oxide, formed by iNOS-transfected astrocytes (pcDNA5iNOS) increased release of lactate $(60 \mathrm{~min})$. Incubation of astrocytes from $\mathrm{nNOS}^{-/-}$mice with LPS-IFN$\gamma$ for $14 \mathrm{~h}$ increased the release of lactate (expressed as the difference between LPS-IFN- $\gamma$-treated and untreated cells) and nitrite, whereas these effects did not occur in astrocytes from iNOS ${ }^{-/-}$mice. Lactate and nitrite concentrations in astrocytes from control mice demonstrated similar results to those obtained from $\mathrm{nNOS}^{-/-}$mice (data not shown). Lactate values in astrocytes from untreated $n \mathrm{NOS}^{-1-}$ and $i \mathrm{NOS}^{-1-}$ mice at $14 \mathrm{~h}$ were $7.78 \pm$ 0.11 and $7.64 \pm 0.29 \mu \mathrm{mol} / 10^{6}$ cells, respectively. (b) Activation of nNOS

cytes and neurons to a similar extent (Fig. 2a). In addition, nitric oxide triggered the accumulation in astrocytes, but not in neurons, of a stable regulatory metabolite(s) able to activate fully PFK1 to $v / V_{\max }$ values up to approximately $0.85-0.95$ in both cell types (Fig. 2a). These results suggest that factor(s) besides PFK1 are responsible for the difference in glycolytic response to nitric oxide in astrocytes and neurons. As $\mathrm{F} 2,6 \mathrm{P}_{2}$ has been reported as the most powerful allosteric activator of PFK1(refs 13-15), we decided to investigate whether it was involved in the activation of PFK1 by nitric oxide. Nitric oxide triggered a rapid (approximately $5 \mathrm{~min}$ ) and time-dependent (up to $60 \mathrm{~min}$ ) accumulation of $\mathrm{F} 2,6 \mathrm{P}_{2}$ in astrocytes (Fig. 2b). Neuronal basal F2,6 $\mathrm{P}_{2}$ concentrations were approximately 4.5 -fold lower, and were not affected by nitric oxide (Fig. 2b).

The synthesis and degradation of $\mathrm{F} 2,6 \mathrm{P}_{2}$ is catalysed by the homodimeric enzyme 6-phosphofructo-2-kinase-fructose-2,6-bisphosphatase (PFK2). This bifunctional enzyme controls the intracellular concentrations of $\mathrm{F} 2,6 \mathrm{P}_{2}$ through regulation of gene expression and phosphorylation states, and hence regulates the glycolytic rate under multiple pathophysiological conditions $s^{6,14,16}$. with glutamate $(100 \mu \mathrm{M}, 15 \mathrm{~min}$ ) failed to alter formation of lactate in neurons. (c) Exposure of both cell types to equal amounts of nitric oxide $(1.4 \mu \mathrm{M})$ for $60 \mathrm{~min}$ increased lactate release in astrocytes, but not in neurons. (d) Nitric oxide increased the $\mathrm{F} 1,6 \mathrm{P}_{2} / \mathrm{F} 6 \mathrm{P}$ ratio in astrocytes, but not in neurons, indicating activation of PFK1. (e) PFK1-specific activity is higher in astrocytes than in neurons. Isoform PFK1.C protein was predominant in astrocytes when compared with neurons, whereas isoforms PFK1.L or PFK1.M were similarly expressed in both cell types. * refers to $p$ $<0.05$ versus corresponding control; \# refers to $p<0.05$ versus corresponding values from iNOS ${ }^{-1-}$.

PFK2 is expressed in a number of tissue-specific isoforms (PFK2.1-4) generated by alternative splicing from four genes (PFKFB 1-4), and these differ in their regulatory properties and kinase-bisphosphatase activity ratio ${ }^{14,15,17}$. Reverse transcription polymerase chain reaction (RT-PCR) analysis of these isoforms demonstrated that astrocytes mainly expressed PFK2.3 and PFK2.4, whereas PFK2.2 was only marginally expressed and expression of PFK2.1 was negligible (Fig. 2c). Of the PFK2 isoforms, the highest kinase-bisphosphatase activity ratio - thus generating more $\mathrm{F} 2,6 \mathrm{P}_{2}-$ is exhibited by PFK2.3, the ubiquitous PFK2 isoform that is present in placenta, brain and tumour cells ${ }^{17,18}$. This resulted in the suggestion that $\mathrm{F} 2,6 \mathrm{P}_{2}$-mediated allosteric activation of PFK1 may be responsible for the higher glycolytic rate demonstrated in those tissues in which PFK2.3 is expressed ${ }^{17,19-22}$. In addition, it has been suggested that the high $\mathrm{F} 2,6 \mathrm{P}_{2}$ concentration found in whole brain tissue has a permissive function in overcoming inhibition of PFK1 by ATP and maintaining this enzyme in an activated state ${ }^{22}$. Our results demonstrate that such permissive PFK1 activation in the brain would be confined to the astrocytes, where there is a greater expression of 

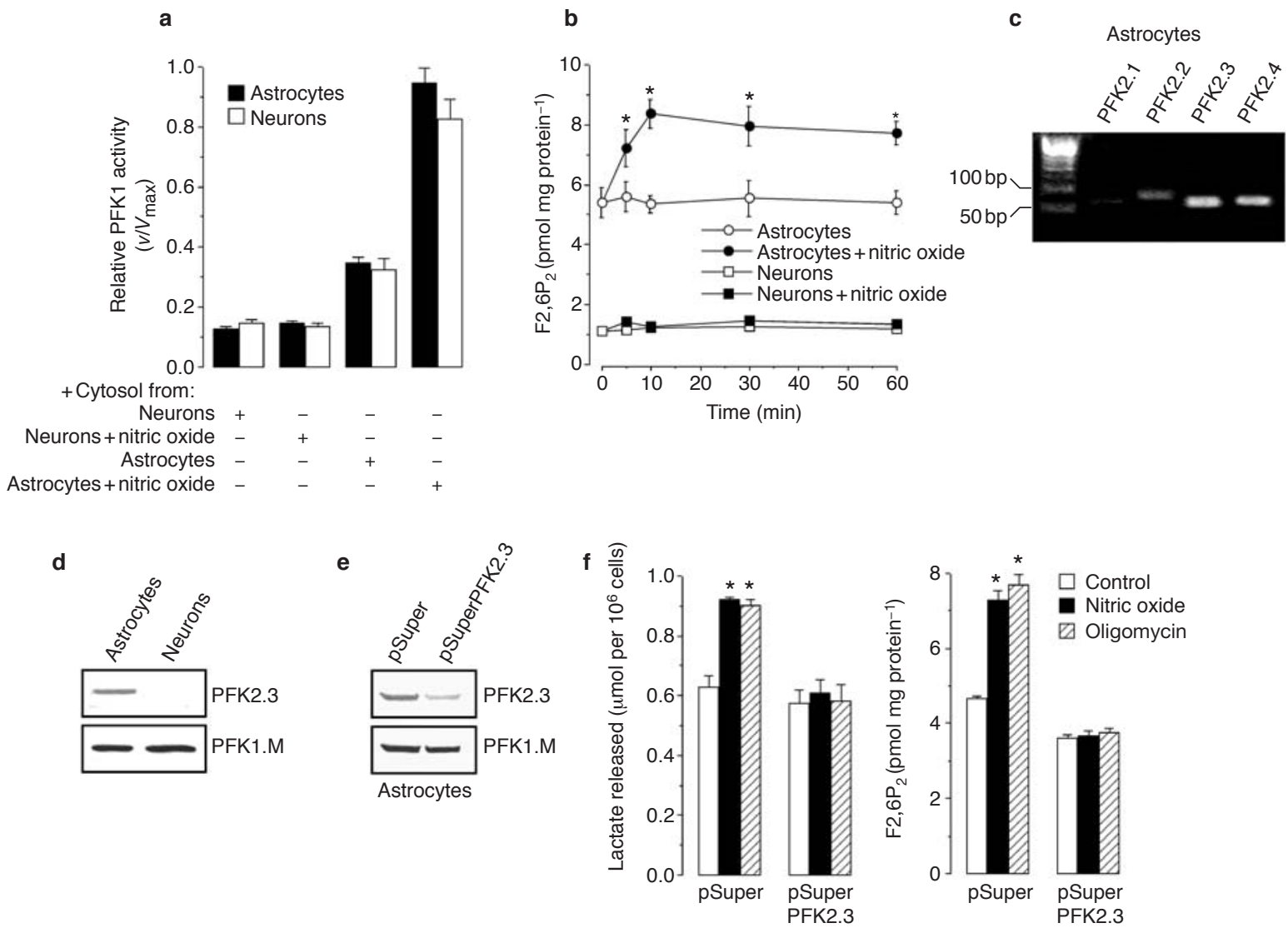

Figure 2 Nitric oxide triggers allosteric PFK1 activation through PFK2. (a) Cytosol from astrocytes directly activated neuronal PFK1. This ability to activate PFK1 was enhanced by treatment of the astrocytes with nitric oxide for $30 \mathrm{~min}$, however, neuronal cytosol was unable to mimic this action. (b) Nitric oxide increased $\mathrm{F} 2,6 \mathrm{P}_{2}$ concentrations in astrocytes, but not in neurons. (c) RT-PCR analysis of PFK2 isoforms in astrocytes demonstrates higher expression of PFK2.3 and PFK2.4 than PFK2.2 or PFK2.1. (d) PFK2.3 protein was expressed in astrocytes, but was undetectable in

PFK2.3 (Fig. 2d) and more F2,6 $\mathrm{P}_{2}$ (Fig. 2b) than in neurons. Treatment with nitric oxide $(30 \mathrm{~min})$ did not affect PFK2.3 protein content in either cell type (data not shown), suggesting that nitric oxide-mediated $\mathrm{F} 2,6 \mathrm{P}_{2}$ increase was a consequence of allosteric PFK2.3 activation.

Next, we investigated whether blockade of PFK2.3 affected the glycolytic response of astrocytes to nitric oxide. As PFK2.3 mRNA contains an AU-rich instability element in its $3^{\prime}$-untranslated region $^{20}$, we used the RNA interference approach to block PFK2.3 protein expression. A double-stranded small interfering RNA-like structure (siRNA) specifically targeted against PFK.2.3 isoform was expressed in primary astrocytes using a pSuper mammalian expression vector ${ }^{9}$. Treatment of astrocytes with siRNA targeted against PFK2.3 (pSuperPFK2.3) for $48 \mathrm{~h}$ severely depleted PFK2.3 protein levels when compared with treatment of cells with the vector alone (pSuper; Fig. 2e). Treatment with nitric oxide increased the release of lactate and intracellular $\mathrm{F} 2,6 \mathrm{P}_{2}$ concentrations in pSuper cells (Fig. 2f), a response which was abolished in pSuperPFK2.3 cells. Furthermore, treatment with oligomycin, an inhibitor of the $\mathrm{F}_{0} \mathrm{~F}_{1}$-ATPase, increased the concentrations of lactate and $\mathrm{F} 2,6 \mathrm{P}_{2}$

neurons. (e) Transfection of astrocytes with a plasmid construct expressing a siRNA targeted against PFK2.3 (pSuperPFK2.3) for $48 \mathrm{~h}$ effectively reduced the concentration of PFK2.3 protein when compared with cells transfected with the vector alone (pSuper). (f) PFK2.3-deficient astrocytes (pSuperPFK2.3) but not control astrocytes (pSuper) failed to increase the release of lactate or the intracellular concentrations of $\mathrm{F} 2,6 \mathrm{P}_{2}$ after treatment with nitric oxide or oligomycin $(5 \mu \mathrm{M})$. * refers to $p<0.05$ versus corresponding control.

under identical conditions; these effects were fully prevented by silencing of PFK2.3 (Fig. 2f). These results strongly suggest that PFK2.3 is essential for nitric oxide-triggered PFK1 upregulation.

The possible involvement of the soluble guanylyl cyclase in the nitric oxide-mediated stimulation of PFK1 and glycolysis in astrocytes was then investigated. ODQ $(1 \mathrm{H}-(1,2,4)$ oxadiazolol- $[4,3-\alpha]-$ quinoxaline-1-one), which prevented NO-mediated elevation of cyclic GMP, had no effect on the nitric oxide-dependent enhancement of the activities of PFK1 and PFK2 or the release of lactate (Fig. 3a). Furthermore, BAY41-2272, which increased cyclic GMP concentrations, had no effect on these parameters either (Fig. 3a). These results suggest that nitric oxide-mediated glycolytic activation in astrocytes is a cyclic GMP-independent phenomenon. However, the inhibitors of mitochondrial respiration, potassium cyanide and oligomycin increased the activities of PFK1 and PFK2 and the release of lactate (Fig. 3a). These results, together with our observation that PFK2.3 silencing prevented oligomycin-mediated enhancement of lactate release and F2,6 $\mathrm{P}_{2}$ concentrations (Fig. 2e), clearly indicate that nitric oxide-mediated activation of glycolysis in astrocytes is a consequence of mitochondrial inhibition. 


\section{LETTERS}

a
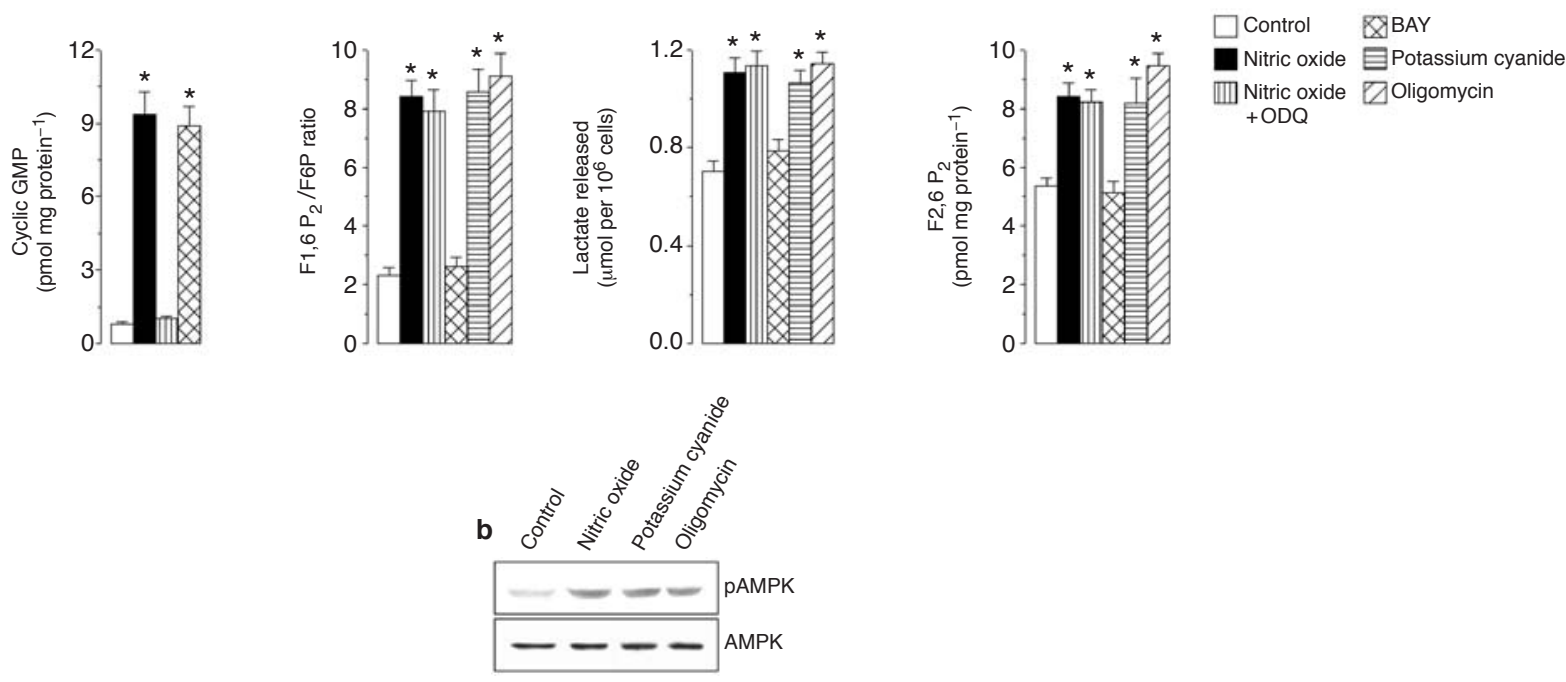

Figure 3 Activation of glycolysis by nitric oxide is cyclic GMP-independent and may involve AMPK phosphorylation. (a) Cyclic GMP was elevated in astrocytes by nitric oxide or BAY41-2272 (BAY, $2 \mu \mathrm{M}$ ). Nitric oxide-mediated increases in $\mathrm{F} 1,6 \mathrm{P}_{2} / \mathrm{F} 6 \mathrm{P}$ ratio, lactate released or $\mathrm{F} 2,6 \mathrm{P}_{2}$ concentrations were not prevented by inhibition of soluble guanylyl cyclase with ODQ $(1 \mu \mathrm{M})$, which prevented elevation of cyclic GMP. Elevation of cyclic GMP by BAY was not accompanied by changes in the $\mathrm{F} 1,6 \mathrm{P}_{2} / \mathrm{F} 6 \mathrm{P}$ ratio, lactate released or $\mathrm{F} 2,6 \mathrm{P}_{2}$ concentrations. (b) Nitric oxide, potassium cyanide $(4 \mathrm{mM})$ or oligomycin $(5 \mu \mathrm{M})$ triggered AMPK- $\alpha$-Thr 172 phosphorylation in astrocytes after $10 \mathrm{~min}$. * refers to $p<0.05$ versus corresponding control.
To investigate this possibility further, we focused on AMP-activated protein kinase (AMPK), which is potently activated after phosphorylation at Thr 172 by the upstream AMPK kinase when the AMP/ATP ratios are elevated ${ }^{23}$. Once activated, AMPK switches on catabolic pathways, both acutely by phosphorylation of metabolic enzymes and chronically by gene expression, and switches off many ATP-consuming processes ${ }^{23}$. Recently, it was reported that AMPK mediates PFK2-Ser 466 phosphorylation, and enzyme activation in the heart in response to ischaemia ${ }^{24}$. We previously reported that inhibition of respiration in astrocytes by nitric oxide inhibits ATP concentrations by approximately 25\% (ref. 5). We therefore investigated whether inhibition of respiration would be sufficient to activate AMPK, and thus switch on glycolysis. As with nitric oxide, potassium cyanide rapidly (within $10 \mathrm{~min}$ ) triggered AMPK- $\alpha-$ Thr 172 phosphorylation, as did oligomycin, a wellknown activator of AMPK (Fig. 3b). To confirm this, we constructed a pSuper vector carrying a siRNA against AMPK (pSuperAMPK). Transfection of astrocytes or HEK293T cells for 72 $h$ with pSuperAMPK efficiently decreased AMPK protein and rendered the cells unable to respond to nitric oxide or oligomycin by increasing the release of lactate or $\mathrm{F} 2,6 \mathrm{P}_{2}$ concentrations (Fig. 4a; see also Supplementary Information, Fig. S1). Furthermore, the increases in lactate (Figs 1a, $4 \mathrm{~b}$ ) and in $\mathrm{F} 2,6 \mathrm{P}_{2}$ concentrations (Fig. $4 \mathrm{~b})$ were observed in LPS-IFN- $\gamma$-treated astrocytes from $n \mathrm{NOS}^{-/-}$, but not in those from $i \mathrm{NOS}^{-/-}$mice. Such effects were prevented by transfection with either pSuperAMPK or pSuperPFK2.3 (Fig. 4b), strongly suggesting the involvement of the AMPK-PFK2 pathway in activation of glycolysis by endogenous nitric oxide in astrocytes. To investigate whether the AMPK-PFK2 pathway is involved in cellular resistance against nitric oxide-mediated cell death ${ }^{5}$, apoptotic cells (annexin $\mathrm{V}^{+}-\mathrm{PI}^{-}$) were quantified by flow cytometry after 60 min treatment with nitric oxide or oligomycin. Reducing the levels of AMPK (pSuperAMPK) or PFK2.3 (pSuperPFK2.3) resulted in a significant increase in apoptosis in nitric oxide- and in oligomycintreated cells (Fig. 4c; see Supplementary Information, Fig. S1). Our results therefore indicate that, in astrocytes, nitric oxide is able to upregulate glycolysis rapidly through a pathway that involves the activation of PFK2.3 by AMPK. The failure of neurons to operate such a mechanism may be a key contributing factor in their susceptibility to neurodegeneration.

\section{METHODS}

Cell cultures. Cortical astrocytes or neurons in primary culture were prepared from neonatal (P0) or fetal (E16) Wistar rats, respectively. Cortical astrocytes were also obtained from $\mathrm{P} 0$ mice lacking either nNOS $\left(n \mathrm{NOS}^{-/-}\right)$ or iNOS $\left(\mathrm{iNOS}^{-/-}\right)$(The Jackson Laboratories, Bar Harbor, ME. Strain names B6.129S4 and B6.129P2, respectively donated by J.R. Alonso, University of Salamanca, Salamanca, Spain and by L. Boscá, Centro Nacional de Investigaciones Cardiovasculares (CNIC; Madrid, Spain). Control mice were C57BL/6J 000664 (bred at the University of Salamanca, Spain). Cells were seeded $\left(2.5 \times 10^{5} \mathrm{cells} / \mathrm{cm}^{2}\right)$ in DMEM (Sigma, Madrid, Spain) supplemented with $10 \%(\mathrm{v} / \mathrm{v})$ foetal calf serum (FCS; Roche Diagnostics, Heidelberg, Germany) and incubated at $37^{\circ} \mathrm{C}$ under a humidified 5\% carbon dioxide-containing atmosphere. For neuronal cultures, 48 $\mathrm{h}$ after plating, the medium was replaced with DMEM supplemented with $5 \%$ horse serum (Sigma) and with $20 \mathrm{mM} \mathrm{D}$-glucose, and on day four, cytosine arabinoside $(10 \mu \mathrm{M})$ was added to prevent non-neuronal proliferation. Cells were used by day eight (neurons) or twelve (astrocytes). Enrichment was approximately $99 \%$ (neurofilament) or approximately $85 \%$ (glial-fibrillary acidic protein) in neurons or astrocytes, respectively. Most other cells in astrocytic cultures were microglia and progenitor cells. HEK293T cells were incubated in DMEM containing 10\% FCS and seeded at $10^{5} \mathrm{cells} / \mathrm{cm}^{2}$ $24 \mathrm{~h}$ before the experiments.

Design and expression of PFK2 and AMPK siRNAs. PFK2.3 or AMPK disruption was achieved by RNA interference using a vector-based siRNA approach ${ }^{9}$. 
a
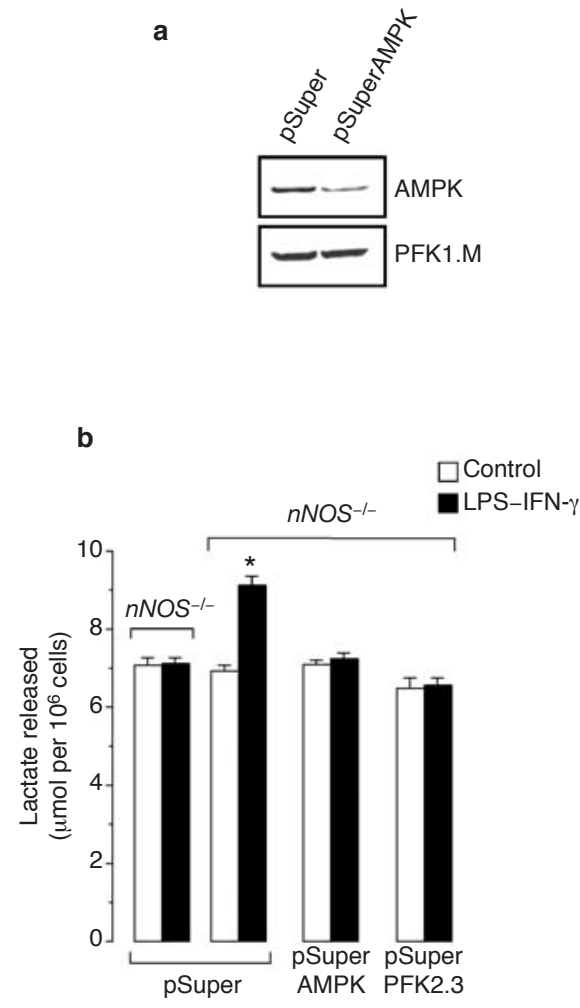
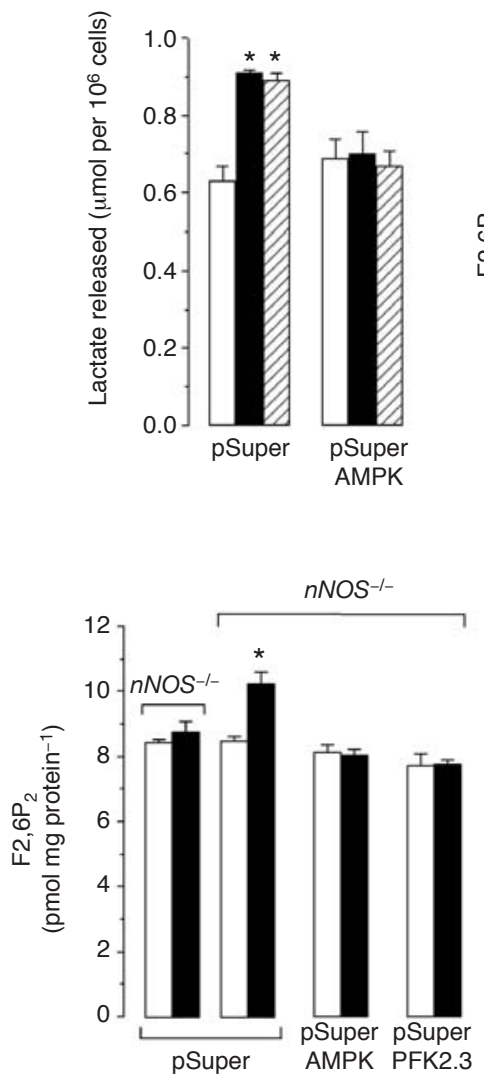

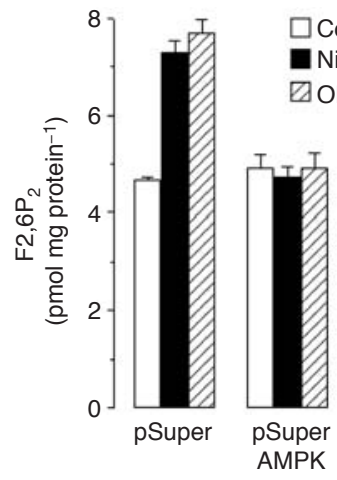

c

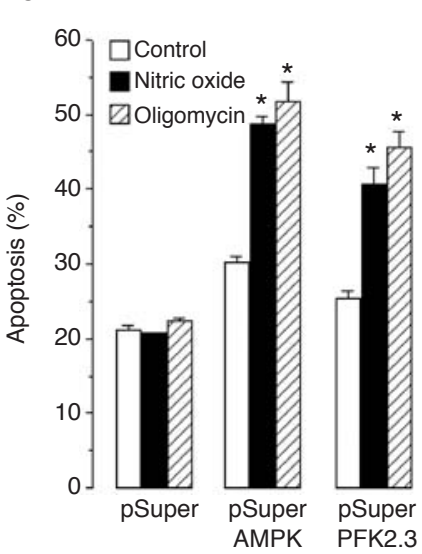

Figure 4 AMPK mediates nitric oxide-dependent glycolytic activation and prevents apoptotic cell death. (a) Transfection of astrocytes with a plasmid construction expressing a siRNA targeted against AMPK- $\alpha$ ( $p$ SuperAMPK) efficiently reduced AMPK- $\alpha$ protein when compared with cells transfected with the vector alone (pSuper). Treatment of AMPK- $\alpha$ deficient astrocytes (pSuperAMPK) with nitric oxide or oligomycin $(5 \mu \mathrm{M})$ prevented the accumulation of lactate and of intracellular $\mathrm{F} 2,6 \mathrm{P}_{2}$ concentrations that was observed with the vector alone (pSuper). (b) Incubation for $14 \mathrm{~h}$ with LPS ( $\left.1 \mu \mathrm{g} \mathrm{ml}^{-1}\right)$ plus IFN- $\gamma\left(100 \mathrm{U} \mathrm{ml}^{-1}\right)$ increased lactate and $\mathrm{F} 2,6 \mathrm{P}_{2}$ concentrations in astrocytes from $n \mathrm{NOS}^{-1-}$, but not in those from iNOS-/- mice. Transfection of $n \mathrm{NOS}^{-/-}$mice astrocytes with pSuperAMPK or pSuperPFK2.3 prevented LPS-IFN- $\gamma$ mediated enhancement of lactate and $\mathrm{F} 2,6 \mathrm{P}_{2}$ concentrations when compared with cells treated with vector alone ( $p S$ uper). Incubation of $n \mathrm{NOS}^{-1}$ - mice astrocytes with LPS-IFN- $\gamma$ after plasmid vector transfection increased nitrite concentrations to values similar to those depicted in Figure 1a (data not shown). (c) Treatment with nitric oxide or oligomycin $(5 \mu \mathrm{M})$ resulted in increased apoptosis (annexin $\mathrm{V}^{+}-\mathrm{PI}^{-}$) of AMPK- $\alpha$ - or PFK2.3-deficient astrocytes, but not their controls. * refers to $p<0.05$ versus corresponding control.
The target sequences were 5'-AAAGCCTCGCATCAACAGC-3' (nt 1908-1926, accession number NM 057135) for the placental PFK2 isoform (PFK2.3), and 5'-GAATCCTGTGACAAGCACA-3' (nt 1311-1329, accession number NM 019142 ) for AMPK- $\alpha_{1}$ catalytic subunit. Both sequences were confirmed for specificity. The forward and reverse synthetic 64-nt oligonucleotides (Isogen Life Technologies, Maarsen, The Netherlands) were designed, annealed and inserted into the BglII/HindIII sites of a green fluorescent protein (GFP) cDNA -carrying pSuper mammalian expression vector (Oligoengine, Seattle, WA) according to the manufacturer's instructions. These constructions express a 19-base pair, 9-nt stem-loop structure (small hairpin RNA) specifically targeted against PFK2.3 or AMPK- $\alpha$ mRNAs. Transfections of primary astrocytes or HEK293T cells were performed with the plasmid constructions (pSuperPFK2.3 or pSuperAMPK) or with the vector alone (pSuper) for 48-72 h using Lipofectamine 2000 (Invitrogen, Madrid, Spain) according to the manufacturer's instructions. The efficiency of transfection was approximately $60 \%$ (astrocytes) or approximately 95\% (HEK293T), as assessed by quantitation of fluorescent cells, and the efficacy of siRNA procedure was confirmed by western blotting.

Incubations of cells with nitric oxide. To achieve nitric oxide production by astrocytes, the cells were transfected (Lipofectamine 2000) with the full- length iNOS cDNA, inserted in the pcDNA5 mammalian expression vector (pcDNA5iNOS construction, provided by J. Mateo, CNIC) in the presence of the nitric oxide synthase inhibitor S-ethylthiourea $(0.5 \mathrm{mM})$. After $24 \mathrm{~h}$, the inhibitor was removed and nitric oxide biosynthesis was confirmed by determination of nitrite released by the cells in buffered Hanks' solution $(5.26 \mathrm{mM}$ potassium chloride, $0.43 \mathrm{mM} \mathrm{KH}_{2} \mathrm{PO}_{4}, 132.4 \mathrm{mM}$ sodium chloride, $4.09 \mathrm{mM}$ $\mathrm{NaHCO}_{3}, 0.33 \mathrm{mM} \mathrm{Na}_{2} \mathrm{HPO}_{4}, 20 \mathrm{mM}$ glucose, $2 \mathrm{mM}$ calcium chloride and 20 $\mathrm{mM}$ HEPES at $\mathrm{pH}$ 7.4). To promote endogenous nitric oxide biosynthesis in astrocytes, these cells were incubated with LPS $\left(0.1-5 \mu \mathrm{g} \mathrm{ml}^{-1}\right)$ plus IFN- $\gamma$ (10-500 $\left.\mathrm{U} \mathrm{ml}^{-1}\right)$ for $14 \mathrm{~h}$. To obtain endogenous nitric oxide production in neurons, the cells were treated with glutamate ( $100 \mu \mathrm{M}$ for $15 \mathrm{~min})$ in buffered Hanks' solution, and nitric oxide formation was confirmed by cyclic GMP determination. To expose the cells to equal amounts of nitric oxide, they were incubated in buffered Hanks' solution containing DETA-NO (Alexis Corporation, San Diego, CA) at $0.5 \mathrm{mM}$, the concentration seen to continuously release approximately $1.4 \mu \mathrm{M}$ of nitric oxide for about $18 \mathrm{~h}$ at $37^{\circ} \mathrm{C}$, as measured by a nitric oxide-sensitive electrode (World Precision Instruments, Sarasota, FL). To ensure immediate exposure of the cells to nitric oxide, all DETA-NO-containing solutions were always pre-incubated in buffered Hanks' solution at $37^{\circ} \mathrm{C}$ for $20 \mathrm{~min}$ before addition to the cells. Under these conditions, nitric oxide inhibited mitochondrial respiration by $85-90 \%$ (ref. 5). As 
controls, incubations were performed in the presence of a degraded DETANO solution $\left(37^{\circ} \mathrm{C}\right.$ for $\left.48 \mathrm{~h}\right)$

Determination of specific activity and allosteric regulation of PFK1. Approximately $10^{7}$ cells were sonicated in $0.2 \mathrm{ml}$ of $50 \mathrm{mM}$ Tris phosphate buffer (at pH 8.0) containing $10 \mathrm{mM}$ dithiothreitol, $1 \mathrm{mM}$ EDTA, $1 \mathrm{mM}$ EGTA, $0.02 \%$ phenylmethylsulfonyl fluoride, $2 \mathrm{mM}$ benzamidine and $10 \mathrm{U}$ $\mathrm{ml}^{-1}$ aprotinin, and centrifuged (20,000g for $30 \mathrm{~min}$ ). PFK1-specific activity was determined in the supernatants by monitoring the rate of $\mathrm{F} 1,6 \mathrm{P}_{2}$ formation from F6P and ATP ${ }^{25}$. To determine the effect of cytosolic regulatory metabolites on PFK1 activity (relative PFK1 activity), supernatants were deproteinized by $10 \mathrm{kDa}$ cut-off filtration (Millipore, Madrid, Spain). Eluates were then immediately used as the metabolite source for PFK1 activity determination, in unfiltered supernatants, in the absence of F6P and ATP $^{12}$. Relative PFK1 activity was expressed as the ratio of PFK1 activity obtained in the presence of equivalent amounts of cytosolic regulatory metabolites obtained from untreated or nitric oxide-treated cells (30 min) versus maximum PFK1 activity (measured in the presence of F6P and ATP, $\left.V_{\max }\right)^{12}$.

Metabolite determinations. F6P and $\mathrm{F} 1,6 \mathrm{P}_{2}$ concentrations were measured in neutralized perchloric extracts obtained from approximately $3 \times 10^{7}$ cells ${ }^{26,27}$. Lactate concentrations were determined in the media ${ }^{26}$. For $\mathrm{F} 2,6 \mathrm{P}_{2}$ determinations, cells extracts were lysed, as described ${ }^{12}$, in $0.1 \mathrm{~N}$ sodium hydroxide and centrifuged (20,000 $\mathrm{g}$ for $20 \mathrm{~min}$ ). An aliquot of the homogenate was used for protein determination ${ }^{28}$ and the remaining sample was heated at $80^{\circ} \mathrm{C}(5 \mathrm{~min})$, centrifuged $(20,000 \mathrm{~g}$ for $20 \mathrm{~min})$ and the resulting supernatant used for the determination of $\mathrm{F} 2,6 \mathrm{P}_{2}$ concentrations ${ }^{27}$. Cyclic GMP was measured by radioimmunoassay (Amersham Biosciences, Buckinghamshire, UK) and nitrite was measured colorimetrically by the Griess reaction.

Western blotting analysis. Aliquots ( $100 \mu \mathrm{g}$ of protein) of cell lysates (in $2 \%$ sodium dodecylsulfate, $2 \mathrm{mM}$ EDTA, $2 \mathrm{mM}$ EGTA, $5 \mathrm{mM}$ Tris, $100 \mu \mathrm{M}$ phenylmethylsulfonyl fluoride, $50 \mu \mathrm{g} \mathrm{ml}^{-1}$ anti-papain, $50 \mu \mathrm{g} \mathrm{ml}^{-1}$ pepstatin, $50 \mu \mathrm{g} \mathrm{ml}^{-1}$ amastatin, $50 \mu \mathrm{g} \mathrm{ml}^{-1}$ leupeptine, $50 \mu \mathrm{g} \mathrm{ml}^{-1}$ bestatin and $50 \mu \mathrm{g} \mathrm{ml}^{-1}$ soybean trypsin inhibitor) were centrifuged $(14,000 \mathrm{~g}, 10 \mathrm{~min})$ and electrophoresed in a SDS/8\% acrylamide gel (MiniProtean ${ }^{\oplus}$, Bio-Rad ) using a BenchMark ${ }^{\mathrm{TM}}$ prestained protein ladder (Isogen Life Technologies). The resolved proteins were transferred electrophoretically to nitrocellulose membranes, which were blocked in 5\% (w/v) low-fat milk in $20 \mathrm{mM}$ Tris $500 \mathrm{mM}$ sodium chloride, $0.1 \%(\mathrm{w} / \mathrm{v}$ ) Tween-20 (at $\mathrm{pH} 7.5$ ) for $1 \mathrm{~h}$, an further incubated with anti-PFK1.L, anti-PFK1.M or anti-PFK1.C (provided by Dr. Emilio Fernández, Universidad de Salamanca, Spain), antiPFK2.3 (gift from Dr. R. Bartrons, University of Barcelona, Barcelona Spain), anti-phospho-AMPK- $\alpha-$ Thr 172 or anti-AMPK- $\alpha$ (Cell Signalling Technology, Beverly, MA). Horsereadish peroxidase (HRP) antirabbit IgGtreated membranes (Santa Cruz Biotechnology, Santa Cruz, CA) were developed by luminol-chemiluminescence.

RT-PCR analysis. Total RNA was purified from astrocytes using a commercially available kit (Sigma). PFK2 mRNA isoform expression was analysed by $4.5 \%$ agarose electrophoresis in DNA-free RNA aliquots $(1 \mu \mathrm{g})$ after RTPCR $\left(50 \mathrm{~min}\right.$ at $48^{\circ} \mathrm{C}$ for reverse transcription; 35 cycles of $30 \mathrm{~s}$ at $95{ }^{\circ} \mathrm{C}$, $30 \mathrm{~s}$ at $55^{\circ} \mathrm{C}$ and $30 \mathrm{~s}$ at $72{ }^{\circ} \mathrm{C} ; 10 \mathrm{~min}$ at $72{ }^{\circ} \mathrm{C}$ ) (Applied Biosystems, Madrid, Spain) using the following forward and reverse oligonucleotides, respectively: 5'-CTCACCCCCTTCCTCCTGTAG-3' and 5'-GGCCATAGCCAGAGTCTGCTT-3' for PFK2.1 (accession number NM 012621; nt 1649-1714); 5'-GGATGGCAAGTTGG-GTTTTTAG-3' and 5'-ACAGAAGAACCAAGTCTATGACTCATG-3' for PFK2.2 (accession number NM 080477; nt 1914-1992); 5'-CCCCGAGCCCACCAAA-3' and $5^{\prime}$ CAGAAGTGGAAGCCACATGCT-3' for PFK2.3 (accession number NM057135; nt 1893-1954); 5'-CACTCCAGGCCACTTCTTCCT-3' and 5' CACTCCAGGCCACTTCTTCCT-3' for PFK2.4 (accession number NM 019333; nt 1477-1543). In no case was a band detected by PCR without reverse transcription.

Flow cytometric analysis of apoptosis. Alexa Fluor 488-conjugated annexin
V-propidium iodide (PI)-based Vybrant Apoptosis Assay kit (Molecular Probes, Eugene, OR) was used, and cells analysed with a FACScalibur flow cytometer (15 mW argon ion laser tuned at $488 \mathrm{~nm}$; CellQuest software, Becton-Dickinson Biosciences, Erembodegen, Belgium). Annexin V-stained cells that were PI-negative (annexin $\mathrm{V}^{+}-\mathrm{PI}^{-}$) were considered to be apoptotic.

Statistical analyses. Significances were assessed by ANOVA followed by the least significant difference multiple range test. The results are the mean \pm SEM values for at least three different culture preparations.

Note: Supplementary Information is available on the Nature Cell Biology website.

\section{ACKNOWLEDGEMENTS}

This work was funded by FIS (A.A.), Fundación CNIC (S.M.) and Ministerio de Ciencia y Tecnología (SAF2001/1961; J.P.B.). S.M. is partially funded by the Medical Research Council (U.K.). Technical assistance from M. DelgadoEsteban and M. Resch (CNIC, Spain) and M. C. Alguero (Hospital Universitario de Salamanca, Spain) are greatly appreciated. We are grateful to A. Higgs for critical evaluation of this paper.

\section{COMPETING FINANCIAL INTERESTS}

The authors declare that they have no competing financial interests.

Received 27 October 2003; accepted 20 November 2003

Published online at http://www.nature.com/naturecellbiology

1. Cleeter, M. W. J., Cooper, J. M., Darley-Usmar, V. M., Moncada, S. \& Schapira, A $H$. Reversible inhibition of cytochrome $c$ oxidase, the terminal enzyme of the mitochondrial respiratory chain, by nitric oxide. Implications for neurodegenerative diseases. FEBS Lett. 345, 50-54 (1994).

2. Brown, G. C. \& Cooper, C. E. Nanomolar concentrations of nitric oxide reversibly inhibit synaptosomal respiration by competing with oxygen at cytochrome oxidase. FEBS Lett. 356, 295-298 (1994).

3. Schweizer, M. \& Richter, C. Nitric oxide potently and reversibly deenergizes mitochondria. Biochem. Biophys. Res. Commun. 204, 169-175 (1994)

4. Bolaños, J. P., Peuchen, S., Heales, S. J. R., Land, J. M. \& Clark, J. B. Nitric oxide-mediated inhibition of the mitochondrial respiratory chain in cultured astrocytes. J. Neurochem. 63, 910-916 (1994).

5. Almeida, A., Almeida, J., Bolaños, J. P. \& Moncada, S. Different responses of astrocytes and neurons to nitric oxide: the role of glycolytically-generated ATP in astrocyte protection. Proc. Natl Acad. Sci. USA 98, 15294-15299 (2001).

6. Uyeda, K. Phosphofructokinase. Adv. Enzymol. Relat. Areas Mol. Biol. 48, 193-244 (1979).

7. Van Schaftingen, E., Lederer, B., Bartrons, R. \& Hers, H. G. A kinetic study of pyrophosphate: fructose-6-phosphate phosphotransferase from potato tubers. Application to a microassay of fructose 2,6-bisphosphate. Eur J Biochem 129 , 191-195 (1982).

8. Hue, L. \& Rider, M. H. Role of fructose 2,6-bisphosphate in the control of glycolysis in mammalian tissues. Biochem. J. 245, 313-324 (1987).

9. Brummelkamp, T. R., Bernards, R. \& Agami, R. A system for stable expression of short interfering RNAs in mammalian cells. Science 296, 550-553 (2002).

10. Brorson, J. R., Schumacker, P. T. \& Zhang, H. P. Nitric oxide acutely inhibits neuronal energy production. J. Neurosci. 19, 147-158 (1999)

11. Sanchez-Martinez, C., Estevez, A. M. \& Aragon, J. J. Phosphofructokinase C isozyme from ascites tumor cells: cloning, expression, and properties. Biochem Biophys Res Commun. 271, 635-640 (2000).

12. Kawaguchi, T., Veech, R. L. \& Uyeda, K. Regulation of energy metabolism in macrophages during hypoxia. Roles of fructose 2,6-bisphosphate and ribose 1,5bisphosphate. J. Biol. Chem. 276, 28554-28561 (2001).

13. Hers, H. G. \& Van Schaftingen, E. Fructose 2,6-bisphosphate 2 years after its discovery. Biochem. J. 206, 1-12 (1982).

14. Pilkis, S. J., Claus, T. H., Kurland, I. J. \& Lange, A. J. 6-Phosphofructo-2 kinase/fructose-2,6-bisphosphatase: a metabolic signaling enzyme. Annu. Rev. Biochem. 64, 799-835 (1995)

15. Okar, D. A. et al. PFK-2/FBPase-2: maker and breaker of the essential biofactor fructose-2,6-bisphosphate. Trends Biochem. Sci. 26, 30-35 (2001).

16. Perez, J. X. et al. Overexpression of fructose 2,6-bisphosphatase decreases glycolysis and delays cell cycle progression. Am. J. Physiol. 279, C1359-C1365 (2000).

17. Manzano, A et al. Molecular cloning, expression, and chromosomal localization of a ubiquitously expressed human 6-phosphofructo-2-kinase/ fructose-2, 6-bisphosphatase gene (PFKFB3). Cytogenet. Cell Genet. 83, 214-217 (1998)

18. Hirata, T., Kato, M., Okamura, N., Fukasawa, M. \& Sakakibara, R. Expression of human placental-type 6-phosphofructo-2-kinase/fructose 2,6-bisphosphatase in various cells and cell lines. Biochem Biophys Res Commun. 242, 680-684 (1998)

19. Sakakibara, R. et al. Characterization of a human placental fructose-6-phosphate 2-kinase/fructose-2,6-bisphosphatase. J. Biochem. 122, 122-128 (1997).

20. Chesney, J. et al. An inducible gene product for 6-phosphofructo-2-kinase with 
an $\mathrm{AU}$-rich instability element: role in tumor cell glycolysis and the Warburg effect. Proc. Natl Acad. Sci. USA 96, 3047-3052 (1999).

21. Navarro-Sabate, A. et al. The human ubiquitous 6-phosphofructo-2-kinase/fructose2,6-bisphosphatase gene (PFKFB3): promoter characterization and genomic structure. Gene 264, 131-138 (2001).

22. Ambrosio, S., Ventura, F., Rosa, J. L. \& Bartons, R. Fructose 2,6-bisphosphate in hypoglycemic rat brain. J. Neurochem. 57, 200-203 (1991).

23. Hardie, D. G. \& Carling, D. The AMP-activated protein kinase-fuel gauge of the mammalian cell. Eur. J. Biochem. 246, 259-273 (1997).

24. Marsin, A. S. et al. Phosphorylation and activation of heart PFK-2 by AMPK has a role in the stimulation of glycolysis during ischaemia. Curr. Biol. 10, 1247-1255 (2000).
25. Ishikawa, E., Ogushi, S., Ishikawa, T. \& Uyeda, K. Activation of mammalian phos phofructokinases by ribose 1,5-bisphosphate. J. Biol. Chem. 265 18875-18878 (1990)

26. Gutmann, I. \& Wahlefeld, A. W. in Methods of Enzymatic Analysis (ed. Bergmeyer, H. U.) 1464-1468 (Verlag Chemie GmbH, Weinheim, 1974).

27. Van Schaftingen, E., Lederer, B., Bartrons, R. \& Hers, H. G. A kinetic study of pyrophosphate: fructose-6-phosphate phosphotransferase from potato tubers Application to a microassay of fructose 2,6-bisphosphate. Eur J Biochem 129, $191-195$ (1982)

28. Lowry, O. H., Rosebrough, N. J., Lewis-Farr, A. \& Randall, R. J. Protein measurement with the Folin phenol reagent. J. Biol. Chem. 193, 265-275 (1951). 


\section{cell biology}

a

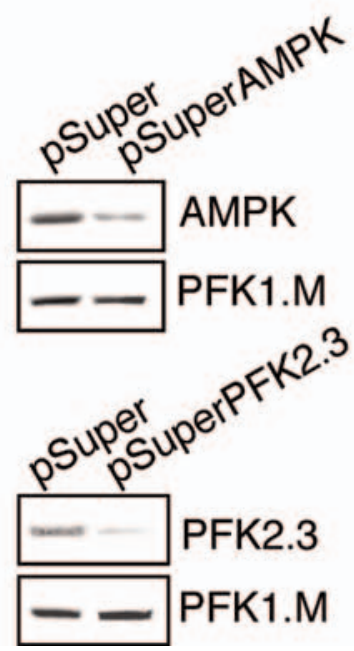

b

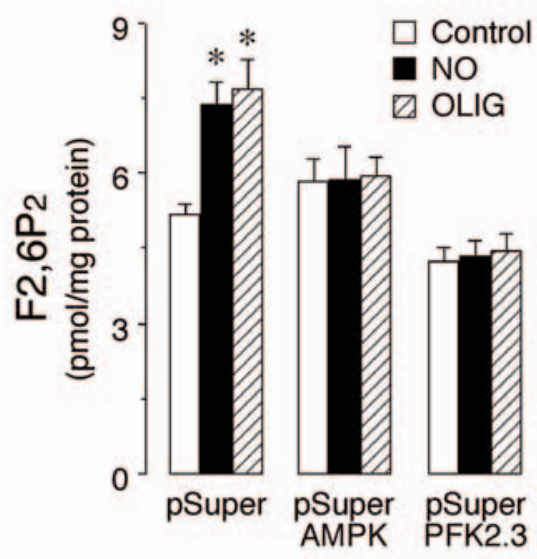

C

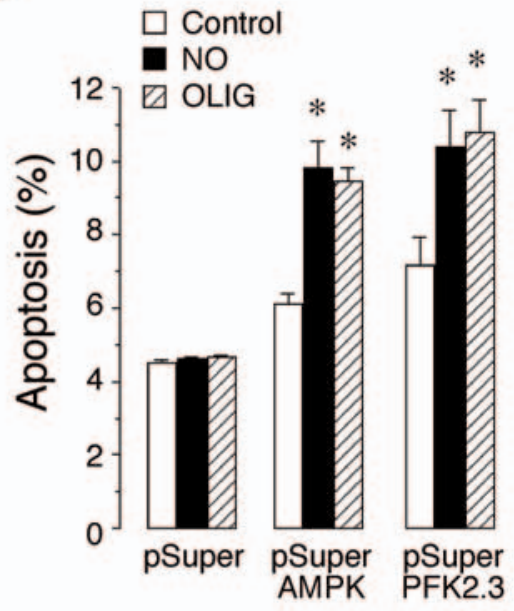

Fig. S1. AMPK- or PFK-2-mediated F2,6P 2 accumulation is involved in NOdependent glycolytic activation, and protects HEK293T cells from apoptosis. (a) Transfection of HEK293T cells with plasmid constructs expressing siRNA targeted against AMPK- $\alpha$ (pSuperAMPK) or PFK2.3

(pSuperPFK2) for $48 \mathrm{~h}$ effectively reduced the proteins AMPK- $\alpha$ or PFK2.3 when compared with cells transfected with the vector alone (pSuper). (b)
HEK293T cells deficient in AMPK- $\alpha$ or PFK2.3 failed to accumulate F2,6P, in response to NO or to oligomycin (OLIG, $5 \mu \mathrm{M})$. (c) Treatment with NO or oligomycin (OLIG $5 \mu \mathrm{M}$ ) led to increased apoptosis (annexin $\mathrm{V}^{+}-\mathrm{PI}^{-}$) of AMPK- $\alpha$ - or PFK2.3-deficient HEK293T cells, but not their controls. $* p<0.05$ versus corresponding control. 